\title{
Medical Image of the Week: Extrapleural Pneumolysis for Tuberculosis
}

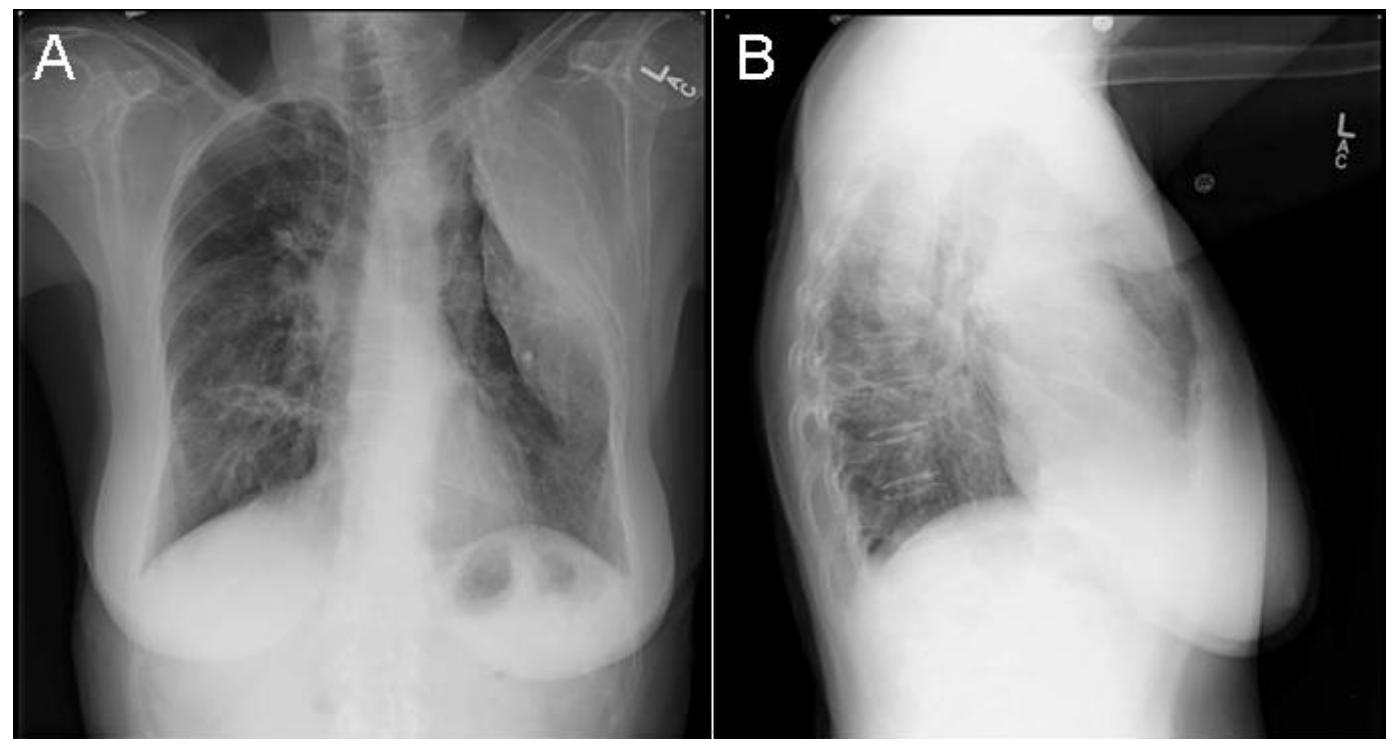

Figure 1. PA (A)/Lateral (B) chest films showing a mass like opacity of the left upper lung field.

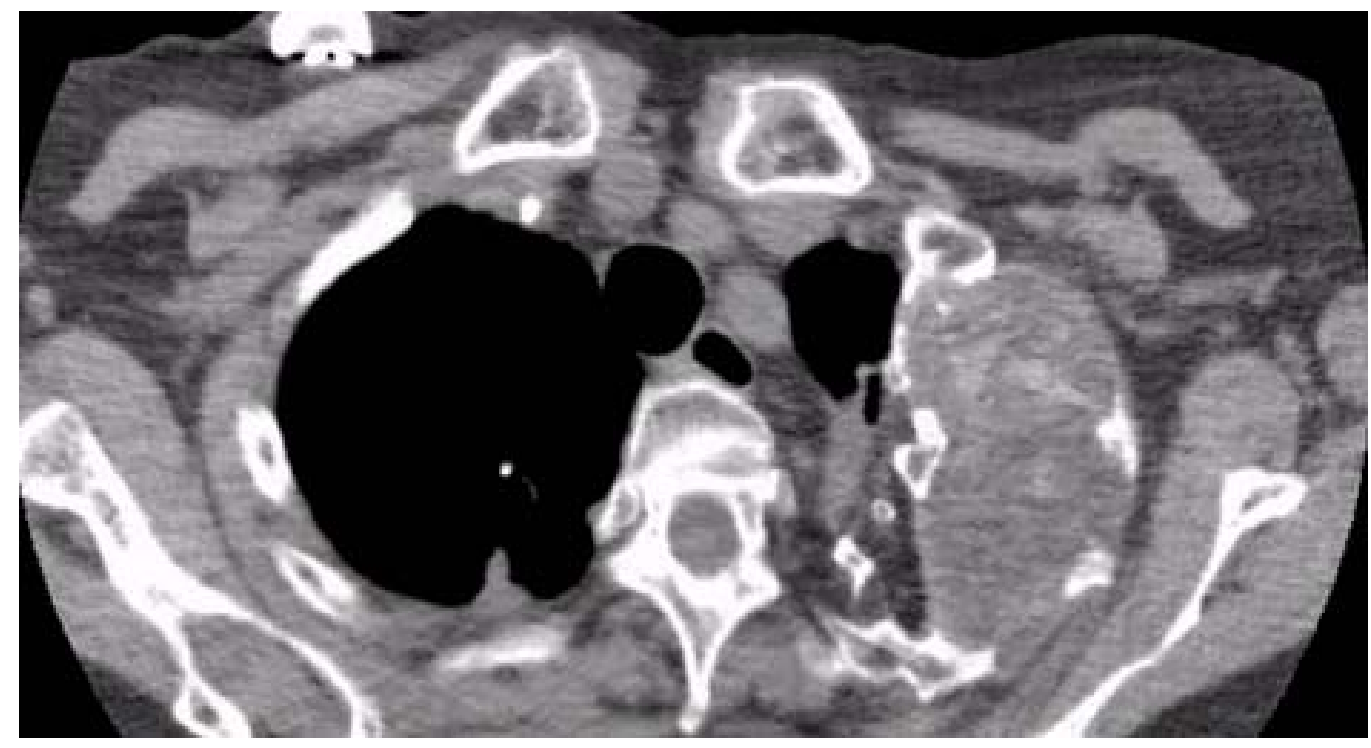

Figure 2. Representative image from the thoracic CT in soft tissue windows showing a well-circumscribed, oval-shaped, heterogeneous density within the left upper and mid anterior chest with some expansion and destruction of overlying ribs.

The advent of antibiotics revolutionized the management of tuberculosis, a disease that even in the 1950s was a top 10 cause of death in the United States. The first drug to be 
developed was streptomycin, approved after a clinical trial in 1946. The following decade saw the addition of ethambutol, rifampin, and isoniazid (1). Though we take for granted the use our multidrug regimens nowadays, physicians once had limited interventions for this frequent and devastating infection. Such interventions included surgical techniques to collapse the affected lobes, starving the mycobacterium of their preferred oxygen rich environment. One such technique was known as plombage, or extrapleural pneumolysis. Plombage is a term derived from the Latin for lead or plumbum and entails the insertion of a space occupying material into the pleural space with subsequent compression of the affected lung portion. This was seen as an alternative to the use of thoracoplasty, which required removal of multiple ribs allowing the chest wall to collapse, leading to deformity and a loss of lung function (2). Though rarely seen now, we present the imaging of an elderly female with endometrial cancer with lung metastasis who interestingly had undergone such a procedure when she developed cavitary tuberculosis as a teenager in 1952.

Tuffler first developed extrapleural pneumolysis in 1891; he placed fat into the pleural cavity reporting successful control of tuberculosis infection. The technique over the subsequent decades became popular especially as a response to the endemic tuberculosis seen post- the Second World War. Many attempts were made to designate an ideal inert material for use. Though unclear in our patient given the remote history of the procedure, published reports include placement of muscle, fat, air, mineral oil, gauze, paraffin, rubber sheeting, and even inflated Lucite balls. Fortunately, complications of the procedure, even decades later, are rarely seen now. Complications listed in the literature, however, do include infection, hemorrhage, fistula formation, migration of material, and even malignancy. Despite its popularity, there were mixed results in effectiveness and variable complication rates, in one series nearly $50 \%$ of patients developed an infection (3). In our patient, it was successful, with no history of recurrence with negative sputum and serologic testing. She did notably report having been treated with a long course of antibiotics as well.

Kareem Ahmad, MD

Department of Internal Medicine

Division of Pulmonary, Critical Care, Sleep, and Allergy Medicine

University of Arizona

Tucson, AZ, USA

\section{References}

1. Zumla A, Nahid P, Cole ST. Advances in the development of new tuberculosis drugs and treatment regimens. Nat Rev Drug Discov. 2013 May;12(5):388-404. [CrossRef] [PubMed]

2. Young $\mathrm{FH}$. Extraperiosteal plombage in the treatment of pulmonary tuberculosis. Thorax. 1958; 13(2):130-5. [CrossRef] [PubMed]

3. Murphy JD, Elrod PD, et al. Surgical treatment of residual cavities following thoracoplasties for tuberculosis. Dis Chest. 1948 Sep-Oct;14(5):694-706. [CrossRef] [PubMed] 